\title{
Recent Trends and Challenges in Microwave Power Dividers
}

\author{
Avneet Kaur and Jyoteesh Malhotra \\ Guru Nanak Dev University-RC-Jalandhar, Punjab, India-144009(s) \\ avneetkaur.53@gmail.com
}

\begin{abstract}
This paper presents a review on recent trends and challenges in the development of power dividing components. Over these years, power dividers have been changing their structures and technology in order to be compatible with the newer changes adopted in designing of communication systems. From being operated as a single-frequency component to being flexible with dual-frequency bands, Wilkinson power dividers have come a long way to become an important and integral part of various RF/microwave devices. The recent technologies for cellular communication have motivated researchers to work on miniaturization and harmonic suppression of power dividers to make them more compact and efficient. Both equal and unequal power dividers are largely employed for $L$ and S-Band applications (GSM, CDMA, Personnel communication systems). Sparameters such a return loss, insertion loss and isolation between output ports plays an important role in their designing.
\end{abstract}

Keywords: Single-frequency, Dual-frequency, Miniaturization, Wilkinson Power Divider.

\section{Introduction}

Front-end components are of an essence to any microwave subsystem, such as transreciever modules, medical instruments, and imaging devices. Hence, a tremendous effort is relentlessly placed to enhance their electrical performance while maintaining a compact size, reasonable fabrication complexity, and above all cost. Power dividers (equal division and unequal division) are important front-end components in many $\mathrm{RF} /$ microwave systems. Hence, the advanced designs and miniaturization of these components are ongoing research topics. Scholars strive to achieve set of targets (e.g., broadened bandwidth, suppressed harmonics, less transmission losses) while minimizing size and fabrication cost. This paper presents a literature survey on these equal and unequal division power dividers.

Power dividers are one of the most widely used passive microwave components for many communication systems. These dividers are used in dividing power from the input to output ports. Traditionally, three types of power dividers are available namely: Resistive Type, T-Junctions and Wilkinson Power Dividers [1]. Resistive type and T-junction type are the least preferred power dividers owing to their poor isolation which is observed between the output ports in comparison with Wilkinson Power divider. WPD, if matched at all ports, is almost lossless and provides high isolation between output ports. However, if any mismatch occurs, the reflected power is dissipated through the isolation resistor. This makes WPD a perfect choice for power division in wireless communication systems. Wilkinson Power Dividers are of two types: equal or $-3 \mathrm{~dB}$ power splitter and unequal division [1]. Equal split WPD find its application in base stations to divide the power equally, in building wireless communication systems, transmission line fault testing ratio measurements and also in signal processing applications. These power dividers are easy to design and implement whereas designing unequal power dividers have fabrication 
limitations of printing thin conductor width. Unequal power dividers are an integral part of the feeding network for antenna array where their performance affects a group of elements rather than an individual element. Thus, their design and size is crucial for the overall system implementation. Figure 1 and 2 shows the conventional diagrams of equal and unequal power dividers. These dividers have a characteristic impedance of $\mathrm{Z}_{0}$ and isolation resistor $\mathrm{R}$. In Figure $2, \mathrm{Z}_{01}$ and $\mathrm{Z}_{02}$ are the high and low transmission line impedances of the circuit respectively.

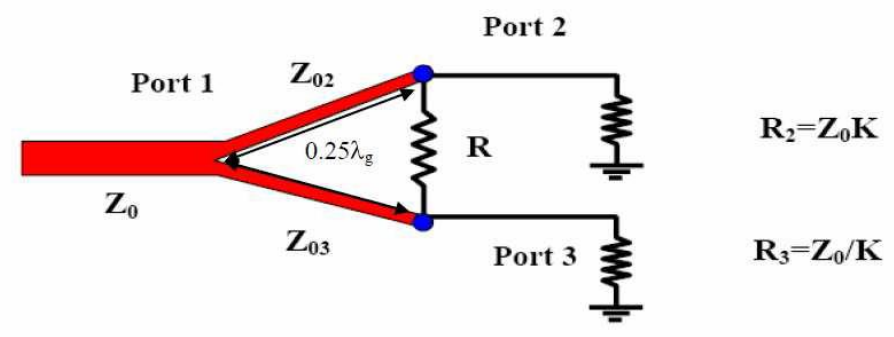

Figure 1. Basic Design of Equal Division Wilkinson Power Divider

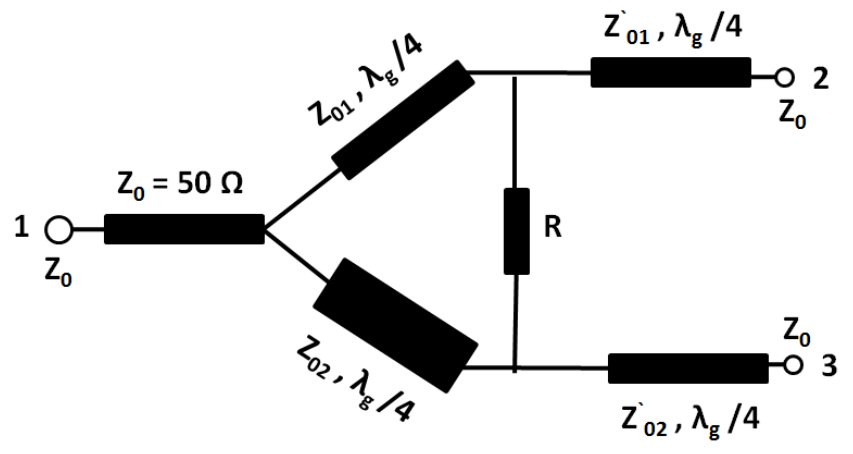

Figure 2. Conventional Circuit of Unequal Wilkinson Power Divider

This paper presents a thorough survey of various designing techniques that have evolved over these years in the implementation of above stated equal and unequal power dividing components employed in modern-day wireless communication systems

\section{Related Work}

\subsection{Equal Division WPD}

The history of the three-port power divider began in 1960 when Wilkinson [2] described a device that separated one signal into $n$ equal signals of equal phase and amplitude, thus, equal division WPD. Theoretically, perfect isolation between all output ports was achieved at one center frequency. In 1965, hybrid with inconsistent amplitude difference of the output signals was presented by Parad and Moynihan [3]. A perfect three-port hybrid property was again achieved at one frequency. In [4], a category of equal-power dividers with isolation and matching at any arbitrary number of frequencies was presented. Further, [5] described three-port hybrids made up of $n$ sections in cascade, where each section was composed of two coupled lossless transmission lines of electrical length $\Phi$ and an intermediate isolation resistor. The analysis of both Ekinge and Cohn were similar. However the difference was that Cohn considered the equal power-division three-port hybrid 
network while Ekinge discussed the three-port hybrid of an arbitrary number of splits.

Due to the fact that conventional WPDs support only a single frequency, their exploitation to wideband systems was limited. For example, the conventional WPD was incompatible with the widely utilized UWB spectrum that spans the 3.1-10.6 $\mathrm{GHz}$ frequency range; and thus, was unemployable to technologies that use this spectrum. Thus, to become employable by these technologies, UWB power dividers were developed. Bialkowski et al. designed a compact UWB out-of-phase uniplanar power divider constructed by a slotline and a microstrip line $\mathrm{T}$-junction along with wideband microstrip to slotline transitions [6]. A miniaturized three-way power divider with UWB feature was presented in [7] by utilizing broadside coupling via multilayer microstrip/slot transitions of elliptical shape. A very similar approach was utilized to design a planar in-phase power divider via circular microstrip/slot transitions for $2-5 \mathrm{GHz}$ wideband applications. Tapered line transformers were also added in the design of an UWB divider which exhibit almost constant input impedance over a wide range of frequencies. However, the resulting circuit area was relatively large in devices. In [8], a reduced-size UWB divider was proposed by employing the transmission lines of a two-stage WPD by incorporating bridged Tcoils. However, the complexity of the design and fabrication was a major drawback.

In order to have modified WPDs with extended bandwidth, different kinds of stubs such as open stubs, delta stubs, radial stubs, and coupled lines were introduced in their designing. But it resulted into utilization of extra transmission lines which was a drawback. Also, with the growth of modern communication systems and crowding in operational frequency bands, the demand for multi-band devices considerably increased which was fulfilled with the designing of dual band power dividers. Dual-frequency functionality of equal division WPD started with Cheng [9], proposing the two-way power divider for dual-band applications. A four-way dual-band Wilkinson Power divider was introduced in [10] which used open stub for matching purposes. All these efforts enhanced spectrum accessibility of the WPD but the increased integration complexity and circuitry occupation were major disadvantages. To overcome this problem of increased divider size and complexity, simple 4-way WPD with meandering technique was proposed which introduced two new configurations of 1:4Wilkinson Power Divider [11]. These size issues and circuit complexity is the major concern for the modern-day miniaturized wireless systems employing equal power dividers and thus, more research and effort is needed in this regard.

\subsection{Unequal Division WPD}

In some applications, such as antenna feed systems where there is need to steer the antenna beam, unequal power division is required and thus, equal-division WPDs cannot be used there. So, for that purpose unequal WPD came into existence. Work on unequal power dividers started with Christopher [12] and team that presented us the design aspects of high power multiport unequal power divider. In [13], general design equations for three-port Unequal power-dividers terminated by different impedances were presented. However, unequal WPDs have a fabrication constraint of high characteristic impedance which is practically impossible to be realized using microstrip technology. So, to overcome such limitations, various structures were reported in [14-19].

For unequal WPD, achieving high characteristic impedance line using DGS contributed a supplementary inductive component to the transmission line which allowed the characteristic impedances above $150 \Omega$ to be easily realizable. Thus, relaxing the fabrication constraints but there was a disadvantage of incompetency when the power splitting ratio was greater than 4:1 [14]. With double-sided parallel 
striplines (DSPSL), it was difficult to maintain a proper distance between the two parallel striplines during their fabrication and thus, formulating these unequal power divider structures using microstrip technology was quite an onerous job [15]. In the conventional power divider, replacing the very low-impedance line with dual transmission lines procreated a new class of unequal power dividers [16]. However, such a method resulted into increased divider size. Application of $\mathrm{T}$-shaped transmission lines was also proposed in place of dual transmission lines. But this solution reduced the operational bandwidth of the power divider.

A new class of unequal power dividers was created with the addition of extra transmission line between the output ports and in series with the isolation resistor. In this, the output ports could directly connect to the power divider without using impedance transformers. However, the power divider bandwidth was reduced a bit. In [17], unequal power divider with high dividing ratio was achieved with the application of loaded transmission line. Optimizing the dimensions of these transmission lines loaded with open or short-circuited stub lead to easy implementation of power divider with high-dividing ratio but with increased coverarea. A compact unequal WPD with arbitrary power division was also proposed by incorporating power divider cells, recombinant structure, low power branch and transformers for matching the circuit. But inculcation of these extra structures resulted into increased divider size. Variable dividing ratio was targeted using DGS, in [18], with the incorporation of varactor diodes in the designing of power divider. However, it resulted into system with large structural area and also fabrication of power divider using DGS was not easy. In [19], coupled-line structure was proposed to realize the high-impedance transmission line for unequal WPD. Application of these coupled-line structures provided a power divider with high dividing ratio and operational bandwidth.

The dual-frequency operation of unequal split WPD was also a hot research topic. Several different structures were proposed in the literature. Initially designed structure proposed for a dual-frequency unequal split WPD did not meet the required conditions to match the output ports $\left(S_{22}\right.$ and $\left.S_{33}\right)$. These conditions play an important role in the design of efficient WPDs. Moreover, a single resistor was used which failed to provide good isolation between the output ports. Other structures were proposed which employed extra transmission line sections and/or reactive components that made the design and its realization even more complicated. In [20], Oraizi presented the design of broadband asymmetric multi-section WPDs. After a rather extensive mathematical derivation, an optimization process was used to find the values of the design parameters.

With the development in microwave communication, different design technologies were adopted to propose efficient Wilkinson Power Dividers. Polystrata Technology and FGC (Finite Ground Co-planar) Technology were adopted to increase the operating frequency-range and RF-Performance (low insertion loss, high return loss and suitable isolation) of these dividers respectively. Similarly, to deal with high fabrication cost of MMIC Wilkinson Divider, lumped capacitors and inductors were introduced in place of transmission lines. However, inculcation of inductor resulted into high transmission loss. So, this problem was solved by replacing inductor with two capacitors. This design resulted into good RF-performance and reduced circuit dimensions.

For each component, all the reviewed literature has been summarized in the following table 1 and 2 respectively. 


\section{Table 1. Important Developments in Design of Equal Power Dividers}

\begin{tabular}{|c|c|c|c|c|c|}
\hline Papers & Return Loss & $\begin{array}{l}\text { Insertion } \\
\text { Loss }\end{array}$ & Isolation & Size & Comments \\
\hline [6] & $\begin{array}{l}\text { In range of } 10 \\
\mathrm{~dB} \text { for the } \\
\text { band of } 3.1- \\
10.6 \mathrm{GHz}\end{array}$ & $\begin{array}{l}\text { Less than } 0.5 \\
\mathrm{~dB}\end{array}$ & $\begin{array}{l}\text { In the range of } \\
8 \mathrm{~dB} \text { for the } \\
\text { band } 3.1-10.6 \\
\mathrm{GHz}\end{array}$ & Not Defined & $\begin{array}{l}\text { Divider uses } \\
\text { extra structures } \\
\text { in form of slots } \\
\text { and microstrips } \\
\text { to achieve its } \\
\text { UWB } \\
\text { performance }\end{array}$ \\
\hline [8] & $\begin{array}{l}\text { Better than } 20 \\
\mathrm{~dB}\end{array}$ & $\begin{array}{l}\text { Less than } 1.25 \\
\mathrm{~dB}\end{array}$ & $1.3 \pm 0.36 \mathrm{~dB}$ & $\begin{array}{l}1.45 \times 0.84 \\
\mathrm{~mm}^{2}\end{array}$ & $\begin{array}{l}\text { The loss can be } \\
\text { reduced by using } \\
\text { wider conductor } \\
\text { trace at the } \\
\text { expense of larger } \\
\text { circuit area. }\end{array}$ \\
\hline [9] & Over $22 \mathrm{~dB}$ & About $3.3 \mathrm{~dB}$ & $\begin{array}{l}\text { Greater than } \\
25 \mathrm{~dB}\end{array}$ & Not defined & $\begin{array}{l}\text { Dual Band WPD } \\
\text { was designed for } \\
\text { the first time }\end{array}$ \\
\hline [10] & $\begin{array}{l}\text { Better than } 15 \\
\text { dB }\end{array}$ & $\pm 0.4 \mathrm{~dB}$ & $\begin{array}{l}\text { Greater than } \\
13 \mathrm{~dB}\end{array}$ & $56 \times 28 \mathrm{~mm}^{2}$ & $\begin{array}{l}\text { T-shaped stub } \\
\text { was used to } \\
\text { provide } \\
\text { additional design } \\
\text { freedom }\end{array}$ \\
\hline [11] & $\begin{array}{l}\text { Better than } 40 \\
\mathrm{~dB}\end{array}$ & $\begin{array}{l}\text { Around }-6 \mathrm{~dB} \\
\text { for both } \\
\text { models }\end{array}$ & $\begin{array}{ll}\text { Around } & -50 \\
\mathrm{~dB} & \end{array}$ & $17 \times 18 \mathrm{~mm}^{2}$ & $\begin{array}{l}\mathrm{T} \text { and Y-type 4- } \\
\text { way WPD are } \\
\text { designed using } \\
\text { meandering } \\
\text { technique }\end{array}$ \\
\hline
\end{tabular}




\section{Table 2. Performance Comparison of Different Design Techniques of Unequal Power Dividers}

\begin{tabular}{|c|c|c|c|c|}
\hline Papers & Return Loss & $\begin{array}{l}\text { Insertion } \\
\text { Loss }\end{array}$ & Isolation & Comments \\
\hline [14] & $\begin{array}{ll}\text { Around } & -40 \\
\mathrm{~dB} & \end{array}$ & -1 and $-7 \mathrm{~dB}$ & About $-40 \mathrm{~dB}$ & $\begin{array}{l}\text { 4:1 unequal } \\
\text { WPD using } \\
\text { DGS is } \\
\text { fabricated }\end{array}$ \\
\hline [15] & $\begin{array}{l}\text { Better than } 20 \\
\text { dB }\end{array}$ & $\begin{array}{l}-1.47 \text { and - } \\
8.51 \mathrm{~dB}\end{array}$ & $\begin{array}{l}\text { Larger than } 20 \\
\text { dB }\end{array}$ & $\begin{array}{l}5: 1 \text { WPD is } \\
\text { designed } \\
\text { using } \\
\text { DSPSL }\end{array}$ \\
\hline$[18]$ & $\begin{array}{l}\text { Better than } 20 \\
\mathrm{~dB}\end{array}$ & $\begin{array}{l}-0.72 \text { and - } \\
8.18 \mathrm{~dB}\end{array}$ & $\begin{array}{l}\text { Better than } 20 \\
\mathrm{~dB}\end{array}$ & $\begin{array}{l}\text { 6:1 DGS } \\
\text { along with } \\
\text { varactor } \\
\text { diode is } \\
\text { used for } \\
\text { designing }\end{array}$ \\
\hline [19] & $\begin{array}{l}\text { Better than }-10 \\
\text { dB }\end{array}$ & $\begin{array}{l}-10.20 \text { and - } \\
9.52 \mathrm{~dB}\end{array}$ & $\begin{array}{l}\text { Better than } 20 \\
\mathrm{~dB}\end{array}$ & $\begin{array}{l}10: 1 \\
\text { Unequal } \\
\text { WPD using } \\
\text { coupled } \\
\text { lines is } \\
\text { proposed }\end{array}$ \\
\hline [20] & Below -17 dB & $\begin{array}{l}3.09 \mathrm{~dB} \text { and } \\
2.84 \mathrm{~dB}\end{array}$ & Around $-12 \mathrm{~dB}$ & $\begin{array}{l}\text { Four dual- } \\
\text { frequency } \\
\text { transformer } \\
\text { are used for } \\
\text { perfect } \\
\text { matching }\end{array}$ \\
\hline
\end{tabular}

\section{Open Issues and Future Scope}

Size issues and circuit complexity are the factors that have to be dealt with in order to provide miniaturize microwave devices. For equal power dividers, size reduction can be achieved by incorporating different space filling curves described in literature and the performance can be improved by curbing the transmission losses with the employment of insulating layers in the design of these microwave devices. In case of unequal power dividers, different design techniques are reported in the literature, however, they don't satisfactorily meet the need of reduced divider size. So, development of small size unequal power dividers with good RFperformance, less complexity in design and smaller structural area is necessary and 
should be worked upon. Different size reduction techniques such as inculcation of meanders or space filling curves should be adopted in their designing to achieve the required compact size dividers. Application of these reduced-size microwave power dividers can help in the designing and implementation of efficient communication systems.

\section{Conclusion}

As concluding remarks, it's profound that the planer microwave components for the system design on chip have matured extensively with the development of the microfabricaton and its reach. These devices are in the right place, as one of the technology with high potential for the system field programmability. Also with the advent of technology the demand for small sized devices with entire SOC has been constantly increasing. The contribution to the research in same direction for the small size, low cost and reduction in design of the system application is done by carefully designing and analyzing the power dividers.

\section{References}

[1] D. Pozar, Microwave Engineering, 3rd ed. Hoboken, New Jersey: John Wiley \& Sons Inc. pp. 308-361, 2005.

[2] E. J. Wilkinson, "An N-Way Hybrid Power Divider," IRE Transactions on Microwave Theory and Techniques, Vol. 8 Issue 1, pp. 116-118, 1960.

[3] L. I. Parad and R. L. Moynihan, "Split-Tee Power Divider", IRE Trans. Microwave Theory Tech., Vol. 8, January 1965, pp. 91-95.

[4] S. B. Cohn, "A Class of Broadband Three-Port TEM-Mode Hybrids", IRE Trans. Microwave Theory Tech., Vol. 16, February 1968, pp. 110-116.

[5] R. B. Ekinge, "A New Method of Synthesizing Matched Broad-Band TEM-Mode Three-Ports", IEEE Trans. Microwave Theory Tech., Vol. 19, January 1971, pp. 81-88.

[6] M. Bialkowski and A. Abbosh, "Design of a compact UWB out-of-phase power divider," IEEE Microw. Wireless Compon. Lett., vol. 17, no. 4, pp. 289-291, Apr. 2007.

[7] A. Abbosh, "A compact UWB three-way power divider," IEEE Microw. Wireless Compon. Lett., vol. 17, no. 8, pp. 598-600, Aug. 2007.

[8] Y.-S. Lin and J.-H. Lee, "Miniature ultra-wideband power divider using bridged Tcoils," IEEE Microw. Wireless Compon. Lett., vol. 22, no. 8, pp. 391-393, Jul. 2012.

[9] Kwok-Keung M. Cheng, Fai-Leung Wong, "A new Wilkinson power divider design for dual band application”, IEEE Microw. and Wireless components letters, vol. 17,no.9, pp.664-666 ,September 2007.

[10] Kamaljeet Singh, Ayan Karmakar, K. Nagachenchaiah, "Dual-band (1:4) Wilkinson Power Divider on Silicon", Journal of Electronics, Vol. 1, No. 1, May 2012.

[11] Avneet Kaur, Harsimran Singh, Dr. Jyoteesh Malhotra, "Design and EM Analysis of 1:4 Wilkinson Power Divider", International Journal of Scientific Research and Engineering, Vol. 3, No. 4, 2015.

[12] Christopher S, Abid Hussain VA, Easwaran MS, Dabade VN, "Design Aspects Of Compact High Power Multiport Unequal Power Dividers", IEEE, 1996.

[13] Hee-Ran Ahn, Ingo Wolff, "General Design Equations of Three-Port Unequal Power-Dividers Terminated by Arbitrary Impedances", IEEE, 2000.

[14] Jong-Sik Lim, Sung-Won Lee, Chul-Soo Kim, Jun-Seok Park, Dal Ahn, and Sangwook Nam, “A $4: 1$ Unequal Wilkinson Power Divider", IEEE Microwave and Wireless Components Letters, Vol. 11, No. 3, March 2001.

[15] Jian-Xin Chen, Quan Xue, "Novel 5:1 Unequal Wilkinson Power Divider Using Offset Double-Sided Parallel-Strip Lines", IEEE Microwave and Wireless Components Letters, Vol. 17, No. 3, March 2007.

[16] Y. Wu, Y. Liu, S. Li, and C. Yu, "Extremely unequal Wilkinson power divider with dual transmission lines," Electronics Letters, Vol. 46, No. 1, 90-91, 2010.

[17] J.-L. Li and B.-Z. Wang, "Novel design of Wilkinson power dividers with arbitrary power division ratios," IEEE Transactions on Industrial Electronics, Vol. 58, No. 6, 2541-2546, Jun. 2011.

[18] Seongmin Oh, Jae-Jin Koo, Mun-Su Hwang, Chunseon Park, Yong-Chae Jeong, Jong-Sik Lim, KwanSun Choi, and Dal Ahn, "An Unequal Wilkinson Power Divider with Variable Dividing Ratio", IEEE MTT-S International Microw. Symp., pp.411-414, June 2007.

[19] Bo Li, Xidong Wu,Wen Wu, "A 10:1 Unequal Wilkinson Power Divider Using Coupled Lines With Two Shorts", IEEE Microwave and Wireless Components Letters, Vol. 19, no. 12, December 2009.

[20] H. Oraizi and A. Sharifi, "Design and optimization of broadband asymmetrical multisection Wilkinson power divider," IEEE Transactions on Microwave Theory and Techniques, Vol. 54, No. 5, 2220-2231, May 2006. 
International Journal of Grid and Distributed Computing Vol. 9, No. 8 (2016) 